\title{
POSSIBILIDADES DE ARTICULAÇÃO TEORIA-E-PRÁTICA POR MEIO DA INVESTIGAÇÃO COLABORATIVA: uma proposta para o ensino de matemática
}

\author{
POSSIBILITIES OF ARTICULATING THEORY AND PRACTICE BY \\ MEANS OF THE COLLABORATIVE RESEARCH: a proposal for the \\ teaching of mathematics
}

Itamar Miranda da Silval Aline Andréia Nicolli2

Tadeu Oliver Gonçalves3

\section{RESUMO}

Este trabalho versa sobre possibilidades de articulação teoria-e-prática, por meio da investigação colaborativa, como uma proposta para o professor enfrentar os desafios do cotidiano dinâmico, utilizando as ferramentas matemáticas. A metodologia fundamenta-se numa pesquisa bibliográfica, por meio da qual estudamos e analisamos vários livros, artigos e dissertações sobre a temática. A partir das leituras e análises, construímos uma proposta para abordar a investigação colaborativa como alternativa de articulação entre a teoria e prática, de forma a permitir mais dinamismo ao ensino de matemática, tendo como perspectiva o desenvolvimento de conhecimentos e práticas pedagógicas que contribuam para uma formação mais ampla, cidadã e crítica dos alunos e do professor. Foram levantadas, também, conjecturas sobre possíveis contribuições da investigação colaborativa entre professor e alunos em utilizar as tendências em Educação Matemática como alternativas diferenciadas. Acreditamos, assim, que este trabalho possa contribuir para uma reflexão sobre a importância da educação matemática na formação do licenciado em matemática,na qual, além do conhecimento disciplinar (conteúdos), são imprescindíveis os conhecimentos pedagógicos, curriculares e experienciais para enfrentar os obstáculos postos em relação ao ensino de matemática.

Palavras chave: Investigação colaborativa; Educação Matemática; Currículo.

\section{ABSTRACT}

This paper is about the possibilities of articulating theory-and-practice by means of collaborative research, as a proposal for the teacher to face the dynamic everyday challenges

${ }^{1}$ Centro de Educação, Letras e Artes - CELA - UFAC

${ }^{2}$ Centro de Educação, Letras e Artes - CELA - UFAC

${ }^{3}$ PPGCEM - IEMCI - UFPA

AMAZÔNIA - Revista de Educação em Ciências e Matemáticas V.8 - no 15 - jul. 2011/dez. 2011, p. 14-26. 
using mathematical tools. The methodology is based on a literature review through which we study and analyze various books, articles and dissertations on the subject. From the readings and analysis, we constructed a proposal to address collaborative research as an alternative link between theory and practice, to allow more dynamism to the teaching of mathematics, in an attempt to develop knowledge and pedagogical practices that contribute to a broader formation, which prepares for citizenship and for being a critical student and teacher. Conjectures were proposed on the possible contributions of collaborative research between teacher and students in using the trends in mathematics education as differentiated alternatives. We believe, therefore, that this work will contribute to a reflection on the importance of mathematics education in the training of students attending a licentiateship in mathematics, in which, in addition to subject knowledge (content), are also essential the pedagogical, curricular and experiential knowledge, to face the obstacles related to the math teaching.

Keywords: Collaborative research; Mathematical Education; Curriculum.

\section{INTRODUÇÃO}

Os questionamentos em relação ao ensino e, sobretudo, ao ensino de matemática são recorrentes nas pesquisas.Nessa direção, vejamos alguns pontos observados por D’Ambrósio (B.,1993): a matemática não é contextualizada, é difícil, é algo pronto e acabado, é uma coleção de verbetes a serem absorvidos pelos alunos, é uma disciplina cumulativa, predeterminada, incontestável, dentre outros4.Recentemente, ministramos um curso de formação continuada a professores do ensino fundamental, e os primeiros diálogos estabelecidos com os cursistas nos deixaram angustiados. Isto porque ouvimos relatos como: "fico triste só em pensar em matemática"; "matemática não é algo para pessoas normais"...Esses e outros motivos que os cursistas nos apresentaram, e ainda apresentam,fazem refletir sobre o fato de estarmos vivendo em pleno século XXI, e vivenciarmos, no entanto, principalmente, em educação matemática,um cenário que nos remete a séculos passados.

Por isso, não podemos deixar de registrar que os aspectos indicados pelos cursistas, sejam por meio de pesquisas, seja por meio de nossas experiências pedagógicas, já poderiam ter sido superados. Porém, na realidade de sala de aula,ainda é comum presenciarmos com certa freqüência essas situações de reclamação em relação à matemática,ressaltando a ineficiência e a ineficácia do 'ensino da matemática'.

Para ratificar o que está posto,importante consideramos as seguintes preocupações, trazidas por Sebastião e Silva (apud ASSUDE, 2002, p.35):

...A modernização do ensino da Matemática terá de ser feita não só quanto a
programas, mas também quanto a métodos de ensino. O professor deve abandonar,
tanto quanto possível, o método expositivo tradicional, em que o papel dos alunos é
quase cem por cento passivos, e procurar, pelo contrário, seguir o método activo,
estabelecendo diálogo com os alunos e estimulando a imaginação destes, de modo a
conduzi-los, sempre que possível, à redescoberta. (...) A Matemática não se reduz a
uma ciência isolada platonicamente de todo o resto. É também instrumento ao
serviço do homem nos mais variados ramos da ciência e da técnica. (...) Na

${ }^{1}$ Essa situação foi observada por nós, recentemente, quando ministramos um curso de formação continuada a professores do ensino fundamental de escolas públicas do Estado do Acre, oferecido pela Universidade Federal do Pará. 
aprendizagem da Matemática não basta ter intuição, compreender, definir, raciocinar. É também indispensável adquirir certos automatismos psicológicos. Isto vale, especialmente, no que se refere a técnicas de cálculo. Tais técnicas são mais perfeitamente assimiladas quando o aluno conhece bem os fundamentos teóricos das mesmas. Mas esse conhecimento não basta: o professor deve insistir para que os alunos se treinem bastante em exercícios equilibrados, que requeiram a aplicação das referidas técnicas.

A preocupação acima não é algo novo, posto que foi apresentada nos anos setenta, e,posteriormente,tem se mantido, sendo acrescida de outras questões relativas ao ensino de matemática também já identificadas e postas em debate, principalmente em âmbito acadêmico. Sendo assim, embora conscientes de encaminhamentos já apresentados e de algumas mudanças já realizadas, pensamos ser ainda pertinente a reflexão da referida colocação, já que é evidente que muitos problemas permanecem e não são/estão restritos ao ensino da matemática, em contexto brasileiro.

\section{ENFOCANDO A PROBLEMÁTICA}

Por convivermos com sujeitos5que não manifestam domínio dos saberes matemáticos, sejam eles disciplinares, curriculares, experienciais ou pedagógicos(TARDIF, 2002), essa investigação tem a intenção de apresentar alternativas que podem se tornar objeto de reflexão na formação desses professores.

Por opção e exeqüibilidade, trataremos das seguintes questões:

(a) Se, segundo Elliot (apud, Contreras 2002), a prática reflexiva do ensino constitui um processo dialético de geração da prática a partir da teoria e da teoria a partir da prática, como articular teoria e prática?

(b) Se, de um lado, a matemática precisa ser contextualizada, dinâmica, conectada com outras áreas de conhecimento, e,de outro, o currículo, os parâmetros, as diretrizes de alguma forma enquadram os conteúdos em uma sequência, em blocos prioritários, como assumir essa dinâmica superando a inércia usual? Essas duas questões serão abordadas concomitantemente, uma em consonância com a outra.

A discussão destas questões passa a constituir o objeto dessa reflexão, que nos remete a considerar a produção teórica sobre as crenças, os saberes profissionais, as práticas dos professores reflexivos, a autonomia de professores, a formação de professores de matemática e o currículo escolar,destacando a influência dos trabalhos de Shulman (1986), Schön (1983, 1988), Tardif (2008), Contreras (2002), Assude (1998) e Ponte (1992).

A literatura específica aponta que Donald Schön $(1983,1988)$ foi, sem dúvida, um dos autores que teve maior peso na difusão do conceito de reflexão. Assim, contribuiu para popularizar e estender ao campo da formação de professores teorias sobre a epistemologia da prática.

Este autor tratou do conceito de reflexão-na-ação, definindo-o como o processo mediante o qual os profissionais (os práticos), nomeadamente os professores, aprendem a partir da análise e interpretação da sua própria atividade. A importância da contribuição de Schön (1983) consiste no fato dele destacar uma característica fundamental da atuação profissional no ensino, qual seja: é uma profissão em que a própria prática conduz à criação

\footnotetext{
${ }^{5}$ Convivemos com alunos das licenciaturas em matemática e pedagogia da Universidade Federal do Acre, que são também, em
} muitos casos, professores da Rede Pública de Ensino Básico do Estado do Acre. 
de um conhecimento específico e ligado à ação, que só pode ser adquirido através do contato com a prática, pois se trata de um conhecimento tácito, pessoal e não sistemático.

Em Clandinin (1986, p. 20), tem-se a definição das seguintes características do conhecimento prático:

... A concepção de conhecimento prático pessoal é a de um conhecimento
experimental, carregado de valor, positivo e orientado para a prática. O
conhecimento prático pessoal adquire-se por tentativas, está sujeito a mudanças, não
pode ser entendido como algo fixo, objetivo e sem alteração... O conhecimento
prático pessoal implica um ponto de vista dialético entre a teoria e a prática. [Grifos
meus]

Compreendemos que Schön (1988) propõe o desenvolvimento de uma nova epistemologia da prática profissional, que situe os problemas técnicos dentro do marco da investigação reflexiva. Tendo esta meta como prioritária, Schön explora as peculiaridades do pensamento prático do profissional, do pensamento que este ativa quando enfrenta os problemas complexos da prática.

Como afirma Yinger (1986, p.275), o êxito do profissional prático depende de sua habilidade para manejar a complexidade e resolver problemas práticos. A habilidade requerida é a interação inteligente e criadora do conhecimento e da técnica.

De acordo com Sacristán (1998), essa habilidade ou conhecimento prático é analisado em profundidade por Schön $(1983,1988)$ como um processo de reflexão na ação ou como um diálogo reflexivo com a situação problemática concreta. Ou seja, não se pode compreender a atividade eficaz do professor quando este enfrenta problemas singulares, complexos, incertos e conflitantes da aula, se não se entendem processos de reflexão na ação.

Contreras (2002), por sua vez, afirma que grande parte da problemática apresentada é consequência de uma racionalidade técnicaque determina a concepção de 'atuação profissional'. Assim, esta racionalidade técnica revela incapacidade de resolver e tratar de tudo que é imprevisível, tudo o que não pode ser interpretado como um processo de decisão e atuação, nem regulado segundo um sistema de raciocínio infalível, a partir de um conjunto de premissas.

Nessa direção, pensamos que a reflexão proposta por Schön(1983, 1988) passa a ser fundamental na constituição do saber experiencial.Segundo Tardif (2008), o saber experiencial se caracteriza como sendo um saber específico que os próprios professores, no exercício de suas práticas e funções de sua profissão, baseados em seu trabalho cotidiano e no conhecimento do meio, desenvolvem. Torna-se necessário, no entanto, que o professor tome consciência desse saber e que o compartilhe com os outros, posto que dominar apenas os saberes disciplinares, curriculares e pedagógicos não é suficiente para dar conta da diversidade de situações encontradas em sala de aula.

\section{Sobre as possibilidades da investigação colaborativa para articular teoria-e-prática}

Bondía (2002) afirma que pensar não é somente "raciocinar" ou "calcular" ou "argumentar", como nos tem sido ensinado algumas vezes, mas é, sobretudo, dar sentido ao que somos e ao que nos acontece.

Tal assertiva nos remete à reflexão sobre a nossa própria experiência pessoal e profissional, já que até pouco tempo atrás acreditávamos que aprender/ensinar matemática significava basicamente raciocinar, pensar coerentemente os axiomas, postulados e teoremas, saber argumentar e demonstrar sem buscar conexão nem com a nossa realidade nem com os 
significados epistemológicos, históricos, sociais e culturais, deixando de reconhecer os interesses que estão envolvidos nessa maneira de pensar.

Ponte (2003), em estudo sobre a relação do professor com a matemática, propõe investigar o professor de matemática, apontando para o fato de que, cada vez mais, deve-se ter como objetivo estudar o professor total na escola total. Fullan e Hargreaves (1992) assinalam, por sua vez, que se faz necessário entender os propósitos de um professor, incluindo as suas crenças, objetivos e valores; o professor como pessoa, com a sua singularidade; o contexto no qual o professor trabalha e a cultura de ensino, isto é, as relações de trabalho que os professores têm com os seus colegas dentro e fora da escola.

Desta forma, esse estudo, na perspectiva da investigação colaborativa, buscará incluir e conectar na prática docente os diferentes domínios do conhecimento do professor definidos por Grossman (1995), quais sejam: (a)conhecimento do conteúdo, (b) conhecimento dos alunos e da aprendizagem,(c) conhecimento da pedagogia em geral, (d) conhecimento do currículo, (e) conhecimento do contexto e (f) conhecimento de si próprio. Para isso, temos que nos envolver em programas de formação continuada com o desenvolvimento de atividades com características etnográficas, ou ainda, em programas colaborativosnos quais o investigador sejaapoio e recurso, de forma tal que, por meio da reflexão, os professores adquiram confiança, façam reflexões, participem de discussões e, possam, aos poucos, se tornarem profissionaiscompetentes.

Acreditamosque ainvestigação colaborativa poderá, neste estudo, viabilizar o ensino e a aprendizagem de matemática. Destacamos, nessa perspectiva, a formapela qual Boavida (2002, p.4-5) trata tais questões, entendendo que a investigação colaborativa permite chegar às seguintes condiçõesagregadoras:

\begin{abstract}
... Juntando diversas pessoas que se empenham num objectivo comum, reúnem-se, só por si, mais energias do que as que possui uma única pessoa, fortalecendo-se, assim, a determinação em agir; Juntando diversas pessoas com experiências, competências e perspectivas diversificadas, reúnem-se mais recursos para concretizar, com êxito, um dado trabalho, havendo, deste modo, um acréscimo de segurança para promover mudanças e iniciar inovações; Juntando diversas pessoas que interagem, dialogam e reflectem em conjunto, criam-se sinergias que possibilitam uma capacidade dereflexão acrescida e um aumento das possibilidades de aprendizagem mútua, permitindo, assim, ir muito mais longe e criando melhores condições para enfrentar, com êxito, as incertezas e obstáculos que surgem.
\end{abstract}

Invocamos a ideia de investigação colaborativa porque buscamos constituir um grupo ativo, no qual professor e alunos participam, investigam e chegam a conclusões, articulando teoria e prática.

A título de exemplo da abordagem de uma investigação colaborativa, utilizamos questões sobre modelagem matemática. Temos nesse caso, um processo pelo qual se busca alcançar o ensino e a aprendizagem da matemática partindo de uma problemática de interesse dos sujeitos. Assim, o professor assume o papel de mediador juntamente com os alunos e pode utilizar ferramentas e objetos matemáticos na tentativa de resolver o problema posto, ou,ainda, por meio de observações e experimentos chegará a modelos matemáticos, ou seja, em parceria, eles partem da teoria para a prática ou vice-versa.

De forma semelhante ao que se realiza na modelagem matemática, pode-se, certamente, abordar outras tendências de ensino em matemática, como, por exemplo, resolução de problemas, história da matemática, etnomatemática, matemática crítica, tratamento da informação, dentre outras, numa perspectiva de investigação colaborativa. Isto 
porque as tendências anteriormente mencionadas também possuem como meta fazer com que os alunos participem do processo e, portanto, compreendam conceitos, definições, e,primordialmente,possam relacioná-las ao seu contexto e tirarem suas conclusões.

Ressaltamos que não estamos defendendo uma abordagem aleatória dos conteúdos matemáticos, isto é, não estamos dizendo que se deve descuidar da lógica das conexões que existem entre os temas, conceitos ou partes específicas. De outra forma, estamos chamando a atenção para a necessidade de levá-los em conta por meio da apresentação dos conteúdos deforma mais adequada, interessante, mostrando a maior quantidade de relações possíveis entre os componentes curriculares da matemática e os problemas reais. Ressaltamos, sobretudo, as aplicações em situações da vida cotidiana, originando experiências variadas e prazerosas, tanto quanto promovendo aprendizagem significativa.

Vale contrapor que a investigação colaborativa enfrenta obstáculos que se estendem desde a negociação do objetivo do projeto até a determinação do caminho a percorrer, a definição do conhecimento necessário para encontrar as soluções pretendidas, a criação e manutenção de relações de confiança entre membros do grupo, o reconhecimento de impasses, a necessidade de novas respostas em função da mudança das condições em que o trabalho se realiza, entre outras.

No entanto, por outro lado, tem-se que reconhecer que a investigação colaborativa propicia uma maior interação entre o professor e alunos e, por isso,torna-se importante levar em consideração algumas das suas características que serão tecidas a seguir:

A primeira característica recorrente na literatura sobre pesquisa colaborativa é a necessidade de confiança. Para Goulet eAubichon(1997, p.118),“a confiança é o primeiro passo para a colaboração". Assim, com confiança e um clima de respeito e cuidado certamente haverá maiores possibilidades de manifestações dos sujeitos, quer a nível pessoal quer profissional. Ou seja, os participantes se sentirão à vontade para questionar abertamente ideias, valores e as ações uns dos outros, respeitando-os e sabendo, igualmente, que o seu trabalho e os seus valores também serão respeitados.

Tratando-se de confiança, parece necessário dizer também que ela está, naturalmente, associada à disponibilidade para ouvir com atenção os outros, à valorização das suas contribuições e ao sentimento de pertença ao grupo,e, para isso, é fundamental que o professor tenha sensibilidade em motivar a confiança do grupo.

Outra característica frequentemente encontrada na literatura é a do diálogo. Como refere Olson (1997), por um lado, é fundamental que seja aceita a voz pessoal, decorrente da experiência, e, por outro lado, é necessário ter sempre presente que nenhuma ideia é definitiva. À medida que uma voz se entrelaça com outras vozes, a compreensão enriquece-se e a conversação torna-se cada vez mais informada. É de notar, no entanto, que o diálogo, mais do que um instrumento de consenso, que serve para anular contradições, deve ser, sobretudo, como diz Christiansen (1999), um instrumento de confronto de ideias e de construção de novas compreensões.

Uma terceira característica fundamental nos projetos colaborativos é a da negociação. É preciso ser capaz de negociar objetivos, modos de trabalho, modos de relacionamento, prioridades e até significados de conceitos fundamentais. Esta negociação deve permear o projeto do princípio ao fim, sendo fundamental nos inevitáveis momentos de crise. Como salientam Christiansenet al. (1997, p. 285), "a chave para uma colaboração bem sucedida é uma negociação aberta da partilha de poder e expectativas relativamente ao papel de cada um dos participantes, à medida que um projeto se desenvolve”. 
Deste modo, um trabalho em colaboração não envolve apenas a aprendizagem relativa ao problema em questão. Envolve, também, a auto aprendizagem e a aprendizagem acerca das relações humanas. Como assevera Olson (1997, p.25):

Cada um virá com seus próprios objetivos, propósitos, necessidades, compreensões e, através do processo de partilha, cada um partirá tendo aprendido a partir do outro. Cada um aprenderá mais acerca de si próprio, mais acerca do outro, e mais acerca do tópico em questão.

\section{POSIÇÃO DESEJÁVEL SOBRE O CURRÍCULO ESCOLAR}

Apresentados os argumentos sobre a investigação colaborativa e a articulação teoria-eprática, por meio do envolvimento do professor e dos alunos, contudo, sem perder de vista tais argumentos, queremos, nesta seção, tratar de alguns aspectos sobre o currículo e a aproximação entre a matemática escolar e a matemática do cotidiano.

Para tanto, iniciaremos chamando a atenção para o fato de que equacionar o ensino escolar da matemática como "transmissão de fatos matemáticos aos alunos" já não faz mais sentido no mundo atual. Porém, ainda é comum observarmos essa prática em salas de aula de matemática, especialmente no ensino médio e superior, nos quais se tem o predomínio de práticas que privilegiam a transmissão de conceitos, definições e fórmulas.

Notamos que, se de um lado, a matemática está cada vez mais presente em todos os fenômenos sociais e cada vez mais a sociedade está sendo regulada por modelos matemáticos complexos, de outro, cada vez menos o cidadão tem que conhecer a matemática que suporta esses modelos.

Assim, o que é exigido é a capacidade de saber lidar com esses modelos, desvendá-los, perceber a sua presença, ser crítico em relação aos modos como são aceitos na sociedade, perceber as intenções e os modos como são produzidos. Neste contexto, a matemática, enquanto disciplina escolar, da forma como está sendo tratada nas escolas, contribui fortemente para a exclusão escolar e social de um número elevadíssimo de crianças e jovens.Essa realidade se apresenta nas mais variadas formas, seja pelas críticas, nem sempre coerentes e condizentes, apresentadas na mídia, seja por meio do resultado de pesquisas desenvolvidas por profissionais da educação que identificam, apontam e questionam os problemas existentes no sistema educacional brasileiro.

Se de um lado, não se pode culpabilizar exclusivamente o professor e sua prática pelas mazelas do sistema educacional, também não se pode, por outro lado, ignorar as responsabilidades profissionais que os professores de matemática possuem. Ou seja, não se pode negar que, muitas vezes, as práticas desenvolvidas nas salas de aula, especialmente nas salas de aula de matemática, têm contribuído com a manutenção do filtro social que foi sendo criado com o ensino da matemática.

Reconhecidas as mazelas do sistema educacional e as responsabilidades dos profissionais que compõem o sistema, importa reconhecer também que não se faz mais possível limitar o papel do professor de matemática ao ato mecânico de ensinar matemática. Faz-se necessário reconhecer a dimensão social, ética e política do/no ensino da matemática; a assunção de que não existe neutralidade nesse ensino e de que se faz cada vez mais indispensável uma nova postura dos professores. 
Assim,neste estudo, ao pensar ou repensar o currículo, poder-se-á, a nosso ver, ajudar o professora perspectivar ${ }^{6}$ uma nova maneira de ensinar, ou ainda, de ensinar matemática.

Importa, dessa forma, chamar a atenção para o fato de que, em vez de um profissional dependente das intenções de quem faz os currículos, o professor precisa assumir uma nova posição: a de profissional que pensa e age com intencionalidade, munido de conhecimento e com capacidade para decidir e agir de acordo com as necessidades da sua situação concreta. Perspectivar o professor, nestes termos, será também um passo importante para promover melhoriasno ensino, principalmente no ensino de matemático.

Não podemos, no entanto, perder de vista que pensar o professor ocupando a posição de agente ativo,exige que pensemos sua formação profissional em termos diferenciados. Assim,para pensar a formação do professor de matemática, numa perspectiva de sujeito capaz de atuar nessa sociedade dinâmica onde a velocidade das informações é cada vez maior e onde se faz cada vez mais necessário diferenciar informação e conhecimento pertinente, vale refletir sobre o que segue:

Conhecer é mais do que obter informações. Significa trabalhar as informações, analisar, organizar, identificar suas fontes, estabelecer as diferenças destas na produção da informação, contextualizar, relacionar as informações e a organização da sociedade, como são utilizadas para perpetuar a desigualdade social. Trabalhar as informações na perspectiva de transformá-las em conhecimento é uma tarefa primordialmente da escola. Realizar o trabalho de analise crítica da informação relacionada à constituição da sociedade e seus valores é trabalho para professor e não para monitor (CONTRERAS, 2002, p.17-18).

Notamos, assim, que pensar um ensino de matemática dinâmico implica na sua contextualização com os fatos sociais, articulando os conceitos, as definições, os teoremas e as teorias com a prática. Ou seja, exige que seja pensada a formação de um profissional preparado cientifica, tecnológica, pedagógica, cultural, técnica e humanamente.

Para tanto, ainda em Contreras (2002), encontramos indicativos de que o professor é responsável pela busca de sua autonomia e que esta não deve ser percebida como isolamento. Ao contrário, autonomia para o autor é algo que se consegue por meio da relação, do intercâmbio com os pares. Dessa consideração surge, a nosso ver, mais um argumento em favor da utilização da abordagem investigativa e colaborativa no ensino de matemática, já que por meio dela poderá ser favorecida (i) a constante formação profissional e o intercâmbio, (ii) a relação entre os pares e a socialização, (iii) o compartilhamento das informações e dos conhecimentos produzidos.

Da mesma forma, importa reconhecer que a flexibilização curricular poderá promover maior diversificação nas propostas de trabalho, admitindo vários modos e níveis de exploração das diferentes tarefas que integram o processo de ensino e de aprendizagem em aulas de matemática.

Por fim, tem que se deixar claro que, neste estudo, buscamos dar maior visibilidade ao currículo micro (aquele pensado e aplicado pelo professor em suas aulas), especialmente por considerar que quanto mais se conhece o micro, melhores serão as possibilidades de agir/alterar/transformar a ação educativa no nível macro. Ou seja, maiores serão as possibilidades de promovermos a construção de um currículo oficial mais aberto e menos prescritivo.

Dando continuidade às reflexões propostas, pretendemos chamar a atenção para o que segue:

${ }^{6} \mathrm{Ou}$ seja, promover a oportunidade de reflexão sobre a importância de sua atuação profissional, seja em sala de aula, seja para além da sala de aula, de forma que possa se tornar um sujeito ativo do processo educacional, nas mais diversas esferas. 
...O problema da flexibilidade deve ser equacionado relativamente ao problema da estabilidade curricular e, nomeadamente, com a escolha de se construir uma cultura comum para os alunos (pelo menos, no ensino obrigatório) e com a criação duma identidade profissional para os professores (ASSUDE, 1998, p.45).

Ante o exposto, parece ser importante que professores - formadores de professores não se coloquem na perspectiva de fornecedores de serviços, ou seja, de profissionais que apenas transferem conhecimento aos estudantes, muitas vezes futuros professores em formação.

Ao contrário, é necessário que professores formadores se percebam como construtores de novas/outras ações científicas e pedagógicas, ou seja, profissionais que propõem situações de ensino planejadas cuidadosamente para atender objetivos de ensino e de aprendizagem claramente estabelecidos, para que, ao se posicionar dessa forma, possam promover aos estudantes, muitas vezes futuros professores em formação,possibilidades de reflexão sobre a sua própria aprendizagem e, principalmente, sobre as implicações dessa aprendizagem para as suas práticas pedagógicas.

Essa postura apresentada, ao chamar a atenção dos professores formadores sobre a importância de se tornarem agentes construtores no curso de processos de ensino e de aprendizagem, deve ser considerada tanto na formação inicial como na formação continuada, especialmente, se os objetivos colimados forem os de promover o desenvolvimento profissional dos futuros professores. Fullan (1993) afirma que o apoio colaborativo, entre professores formadores e seus estudantes, muitas vezes futuros professores em formação é um componente necessário para o desenvolvimento profissional.

Temos, nesse caso, a investigação colaborativas e apresentando, mais uma vez, como uma alternativa viável,como uma abordagem capaz de viabilizar compreensão mais crítica a respeito do desenvolvimento profissional e, por consequência, dos currículos, levando em conta os parâmetros e diretrizes, bem como podendo permitir ao professor a flexibilidade desejável para mobilizar objetos matemáticos, tornando-os ferramentas eficazes não só para a resolução de situações matemáticas, mas, sobretudo,para a interpretação do mundo no qual estamos inseridos.

Para dar continuidade às reflexões apresentadas neste texto sobre a formação de professores de matemática e as relações deste processo formativo com questões sociais,faremos referência à Educação Matemática Crítica e ao defensor de suas ideias, Skovsmose (2001, p.101), que apresenta uma ideia mais geral e unificadora de educação crítica,vejamos:

\footnotetext{
...Para que a educação, tanto como prática quanto como pesquisa, seja crítica, ela deve discutir condições básicas para a obtenção do conhecimento, deve estar a par dos problemas sociais, das desigualdades, da supressão, etc.,e deve tentar fazer da educação uma força social progressivamente ativa.
}

Para este autor, uma educação matemática crítica engloba aspectos tais como: (a) relação professor-aluno não autoritária, (b) envolvimento dos estudantes no controle do processo educacional e (c) relação dialógica e democrática entre professores. Ao atribuir a estudantes e professores competência crítica, Skovsmose (2001) considera que os estudantes têm experiências prévias que, no diálogo com o professor, são relevantes para o processo educacional. Nesses termos, a investigação colaborativa apresenta-se como possibilidade de diálogo, seja entre professores, seja entre os professores e seus estudantes.

No que se refere, no entanto, ao estabelecimento de certa distância crítica do conteúdo, pode-se debater sua aplicabilidade, tanto quanto os interesses que estão por trás 
deles e as possíveis aplicações às demandas da sociedade. Finalmente, direcionando o ensino para problemas que se encontram "além do contexto educacional" e que são relevantes para o aluno e a sociedade, impõe-se à educação um engajamento crítico.

Nessa mesma vertente, os autores Skovsmose e Valero (2001, p.43) destacam que é importante que a educação matemática ajude a identificar os diferentes papéis e funções possíveis da matemática à medida que a sociedade avança e se torna mais complexa.

O exposto ratifica a importância de articulação teoria e prática e da dinâmica versus inércia, no ensino de matemática, por meio de investigação colaborativa. No entanto, com o intuito de ampliar a discussão parece ser pertinente, ainda, chamar a atenção para o que segue:

Primeiro, para o fato de que as possibilidades de inovação nas instituições escolares não podem ser propostas sem a construção de um novo conceito de profissionalismo docente, que deve romper com a inércia das práticas do passado e que são assumidas passivamente como elementos intrínsecos à profissão. Dito de outra forma, o professor de matemática precisa conhecer o contexto no qual atua, para planejar o processo de ensino em termos dinâmicos, flexíveis e críticos, promovendo processos de inovação e transformação. Para Aragão (2003), para ser professor não basta conhecer a matéria, ter conhecimento específico, é preciso, sobretudo, ter competência ou ser competente para, em termos autônomos, transformar, por exemplo, o saber disciplinar em conteúdos acessíveis aos alunos, colocandoos em disponibilidade pedagógica por meio do ensino, para serem aprendidos.

Um segundo aspecto que precisa ser considerado é o proposto por Imbernón (2010, p.25) relativo ao profissional de educação como um agente dinâmico, social e curricular, a saber:

... [ Este profissional]...deve ter a permissão de tomar decisões educativas, éticas e morais, desenvolver o currículo em um contexto determinado e elaborar projetos e matérias curriculares em colaboração com colegas, situando o processo em um contexto específico controlado pelo próprio coletivo.

Tem-se, portanto, mais uma justificativa para a consideração da abordagem de investigação colaborativa para se pensar o currículo de maneira flexível, de forma tal que os conteúdos possam ser adaptados às necessidades do contexto escolar, das intenções do professor e dos interesses dos estudantes.

\section{CONSIDERAÇÕES FINAIS}

Nesse espaço, muito brevemente, pretendemos chamar a atenção para o fato de que a investigação colaborativa exige, primeiramente, que se tenha uma melhor percepção dos estudantes, nas mais variadas dimensões do ensino e da aprendizagem, isso porque se torna imprescindível que esses sejam compreendidos como sujeitos ativos do/no processo científico-pedagógico que ocorre em âmbito escolar.Este tipo de investigação docente, certamente, permitirá que sejam estabelecidas relações entre o conhecimento dos professores e o conhecimento dos estudantes, bem como com o contexto escolar.Além disso, serão fornecidos elementos preciosos de análise para a discussão de possibilidades e limitações 
deste tipo de investigação quando se trata do desenvolvimento de estudos sobre o ensino e a aprendizagem da matemática, na formação inicial ou na formação continuada de professores.

Assim sendo, mais do que informar matematicamente, é necessário, de acordo com Skovsmose (2001), educar criticamente por meio da matemática. Dito de outra forma, ao educar criticamente por meio da matemática, inclui-se a intenção de que as atividades escolares promovam reflexão sobre três questões fundamentais, a saber: (a) natureza crítica da matemática, (b) suas aplicações no cotidiano e (c) sua importância para o exercício da cidadania. A título de exemplo, acerca da importância das três questões explicitadas, importa chamar a atenção para o fato de que, cotidianamente, a sociedade entra em contato com explicações nas quais se utilizam "números" e outros dados matemáticos para justificar determinadas ações, atitudes, especialmente, governamentais.

Assim, ao pensar outra proposta de ensino de matemática, pretendemos, sobretudo,ampliar o debate, contemplando questões que extrapolam os limites dos números.Pensar o ensino de matemática, por esse viés, é pensar em uma proposta de ensino que contribui com a formação de sujeitos mais críticos, politizados e, por consequência, para a formação de cidadãos mais atuantes.

\section{REFERÊNCIAS}

ARAGÃO, Rosália M. R. de. Questões de Autonomia e de Competência: Relações de qualidade educativa do trabalho docente.Anais do XXI Simpósio Brasileiro de Administração da Educação. III Congresso Luso-Brasileiro de Política e Administração da Educação, ANPAE, Recife, Nov.2003.

ASSUDE, Tereza.Elementos de reflexão sobrea análise e o desenvolvimento curricular.Versailles: IREM, 1998.

BOAVIDA, A. M., PONTE, J. P. Investigação colaborativa: potencialidades e problemas. In: GTI (Org.) Reflectir e investigar sobre a prática profissional. Lisboa: APM, p. 43-55, 2002.

BONDÍA, J. L. Notas sobre a experiência e o saber da experiência. Revista Brasileira de Educação. n. 19, p. 20-28. jan/fev/mar/abr. 2002.

CHRISTIANSEN, H. [et all]. Making the connections.In:CHRISTIANSEN,H. [et all]Recreating relationships: Collaboration and educational reform. New York, NY: State University of New York Press.p. 283-292, 1997.

CHRISTIANSEN,I.Are theories in mathematics education of any use to practice?For the Learning of Mathematics, 19(1), 1999, p. 20-23.

CLANDININ, J.S. Classroom practice: teacher Images in action. London: Falmer Press, 1986.

CONTRERAS, José. A autonomia de professores. São Paulo: Cortez, 2002. 
FULLAN, M. Change forces: Probing the depths of educational reform. London: The Falmer Press, 1993.

FULLAN, M.,HARGREAVES, A. Teacher development and educational change.In M. London: Falmer Press, 1992, p.1-9.

GOULET, L., AUBICHON, B. Learning collaboration: Research in a first nations teacher education program. In: Christiansen, $\mathrm{H}$ [et all]. Recreating relationships: Collaboration and educational reform. New York, NY: State University of New York Press, p. 115-127, 1997.GROSSMAN, P. Teachers' knowledge.In:ANDERSON, L. (Ed.), International encyclopedia of teaching and teacher education (2nd edition). Pergamon.

IMBERNÓN, Francisco. Formação docente e profissional: formar-se para mudança e incerteza. São Paulo: Cortez, 2010.

OLSON, M. Collaboration: An epistemological shift. In: Christiansen, H. [et all] Recreating relationships: Collaboration and educational reform. New York, NY: State University of New York Press.p. 13-25, 1997.

PONTE, J. P. Concepções dos professores de matemática e processos de formação. In Educação Matemática: Temas de Investigação. Lisboa: IIE, p. 185-239, 1992.

PONTE, J. P., SERRAZINA, M. L. Professores e formadores investigam a sua própria prática.Zetetiké, 11(20), p. 51-84, 2003.

SCHÖN, D. A. Educando o profissional reflexivo: um novo design para o ensino $e$ aprendizagem.Tradução de Roberto Cataldo Costa.Porto Alegre: Artes Médicas Sul, 2000.

SHULMAN, L. Those who understand: Knowledge growth in teaching. EducationalResearcher, 15, 4-14, 1986.

SIMÕES, C. O desenvolvimento do professor e a construção do conhecimento pedagógico. Aveiro: Fundação João Jacinto de Magalhães, 1996.

SKOVSMOSE, Ole. Educação matemática crítica: a questão da democracia. São Paulo: Papirus, 2001.

SKOVSMOSE, O.; VALERO, P. Breaking political neutrality: the critical engagement of mathematics education with democracy. In: ATWEH, B. [et all] (ed.). Sociocultural research on mathematics education: an international perspective. New Jersey: LEA, p. 37-55, 2001. 
TAVARES, J. A aprendizagem como construção de conhecimento pela via da resolução de problemas e da reflexão. Aveiro: CIDInE, 1992.

YINGER,R. Examining thought in action: a theoretical and methodological critique of research on interactive teaching. Teaching and teacher education.Vol.2.n. 3. 1986, p. 263-282. 